\title{
Smad3-mSin3A-HDAC1 Complex
} is Required for TGF- $\beta 1$-Induced Transcriptional Inhibition of PPARy in Mouse Cardiac Fibroblasts

\author{
Kaizheng Gonga,b Mingxing Chen ${ }^{a}$ Rujun Lia Yanghong He ${ }^{a}$ Huajiang Zhu ${ }^{a}$ \\ Dan Yao ${ }^{a}$ Suzanne Oparilc Zhengang Zhang ${ }^{d}$ \\ aDepartment of Cardiology, the Affiliated Hospital of Yangzhou University, bJiangsu key laboratory of \\ Integrative medicine for the control of geriatrics, Yangzhou, China; 'Hypertension and Vascular Biology \\ Program, Division of Cardiovascular Diseases, University of Alabama at Birmingham, Birmingham, AL, \\ USA; dDepartment of Clinical Medicine, Yangzhou University Medical College, Yangzhou, China
}

\section{Key Words}

Cardiac fibrosis $\cdot \operatorname{PPAR} \gamma \cdot \operatorname{Smad} 3 \cdot \mathrm{mSin} 3 \mathrm{~A} \cdot \mathrm{TGF}-\beta$

\begin{abstract}
Background: We have recently demonstrated that activated transforming growth factor- $\beta$ (TGF- $\beta$ ) signaling suppresses myocardial peroxisome proliferator-activated receptor $\gamma$ (PPAR $\gamma$ ) expression in the pressure overloaded heart. In this study, we aim to further define the molecular mechanisms that underlie TGF- $\beta$-induced PPAR $\gamma$ transcriptional inhibition. Methods: Adult mouse cardiac fibroblasts were isolated and cultured. PPAR $\gamma$ promoter activity was measured by the dual-Luciferase reporter assay. Interactions between transcription factors and the target gene were identified. Results: In cultured cardiac fibroblasts transfected with a plasmid containing a human PPARy promoter, co-transfection of Smad3 and Smad4, but not Smad2, plasmids significantly enhanced TGF- $\beta 1$-induced inhibition of PPAR $\gamma$ promoter activity. Promoter deletion analysis and site-directed mutagenesis assays defined two Smad binding elements on the promoter of the PPAR $y$ gene. Utilizing chromatin immunoprecipitation analysis and DNA-affinity precipitation methods, we demonstrated that the transcriptional regulatory complex consisting of Smad3, mSin3A and HDAC1 bound to the promoter of the PPAR $y$ gene in cardiac fibroblasts in response to TGF- $\beta 1$ stimulation. Either silencing endogenous $\mathrm{mSin} 3 \mathrm{~A}$ expression by Lentivirus-mediated transduction of mSin3A shRNA or pretreatment with the specific HDAC1 inhibitor MS-275 effectively attenuated TGF- $\beta$-induced transcriptional suppression of PPAR $\gamma$. Conclusion: These results suggest that TGF- $\beta 1$-induced inhibition of PPAR $y$ transcription depends on formation of a functional transcriptional regulatory complex that includes Smad3, mSin3A and HDAC1 at the PPARY promoter.




\section{Cellular Physiology Cell Physiol Biochem 2016;40:908-920

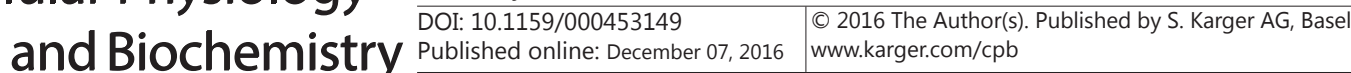 \\ Gong et al.: mSin3A-HDAC1-Smad3 Mediates PPAR $\gamma$ Inhibition by TGF- $\beta$}

\section{Introduction}

Accumulating evidence has shown that the transcription factor peroxisome proliferator-activated receptor gamma (PPAR $\gamma$ ) is involved in the pathogenesis of a variety of pathophysiologic processes, including fibrotic, hypertrophic, and inflammatory responses of the heart to hemodynamic stress $[1,2]$. In mouse myocardium, over-expression of PPAR $\gamma$ led to a dilated cardiomyopathy associated with increased lipid and glycogen stores and distorted mitochondrial architecture [3]. Clinically, ischemic or dilated cardiomyopathy has been characterized by significant up-regulation of PPAR $\gamma$ expression [4]. In contrast, cardiomyocyte-specific deletion of PPAR $\gamma$ has been shown to induce cardiac hypertrophy with preserved left ventricular systolic function [5], while, targeted deletion of PPAR $\gamma$ in smooth musce cells has been associated with pulmonary hypertension and right ventricular hypertrophy [6]. These studies suggest that PPAR $\gamma$ functions as an endogenous modulator of cardiovascular remodeling and that an appropriate level of PPAR $\gamma$ expression in the cardiovascular system is needed to maintain normal cardiovascular homeostasis.

In heart, the pro-fibrogenic transforming growth factor (TGF)- $\beta$ is secreted by cardiac fibroblasts (CFs) and cardiomyocytes in response to pressure overload stress $[7,8]$. TGF- $\beta$ signals through the membrane bound TGF- $\beta$ receptors type I and II. When the receptors are activated, the downstream signaling molecules Smad2 and Smad3 are phosphorylated, bind to $\operatorname{Smad} 4$, and translocate to the nucleus [9]. The Smad2/3/4 complex then binds to response elements in the promoter regions of target genes and regulates transcriptional events. Apart from the induction of target genes such as plasminogen activator inhibitor 1 and collagen I, Smad2/3 participate in transcriptional inhibition with the help of transcriptional corepressors such as Evi-1, SIP-1, c-Ski and mSin3 [10].

We have recently used a transgenic mouse model that expresses dominant negative TGF- $\beta$ type II receptors (DnTGF $\beta$ RII) to demonstrate that pressure overload stress suppresses endogenous myocardial PPAR $\gamma$ expression in wild type mice and that this suppressive effect is abolished in DnTGF $\beta$ RII mutants, in which TGF- $\beta$ /Smad3 signaling is attenuated [11]. In cultured adult mouse CFs, we also demonstrated that TGF- $\beta 1$ treatment increased binding of Smad $2 / 3$ to the PPAR $\gamma$ promoter, then suppressed expression of PPAR $\gamma$ at the protein and mRNA levels, suggesting a role for TGF- $\beta /$ Smad signaling in regulation of PPAR $\gamma$ expression [11]. The detailed molecular mechanisms underlying TGF- $\beta$-induced inhibition of PPAR $\gamma$ transcription remain unclear.

In the present study, we demonstrated that Smad3, but not Smad2, is required for inhibition of PPAR $\gamma$ transcription by recruiting the mSin3A/HDAC1 transcriptional corepressor complex to the promoter of PPAR $\gamma$. Specifically, we observed that: 1) Transfection of Smad3, but not Smad2, plasmids enhanced TGF- $\beta 1$-induced inhibition of PPAR $\gamma$ promoter activity. 2) mSin $3 A$ and HDAC1 bound to the promoter of the PPAR $\gamma$ gene in cardiac fibroblasts in response to TGF- $\beta 1$ stimulation. 3) Silencing endogenous $\mathrm{mSin} 3 \mathrm{~A}$ expression by lentivirus-mediated transfection of $\mathrm{mSin} 3 \mathrm{~A}$ shRNA or pretreatment with the specific HDAC1 inhibitor MS-275 attenuated TGF- $\beta$-induced transcriptional suppression of PPAR $\gamma$.

\section{Materials and Methods}

\section{Cardiac fibroblast preparation}

CFs were isolated from hearts of adult male C57BL/6 mice as we have described previously [12]. Briefly, mice were euthanized by anesthesia with intraperiotoneal ketamine $(80 \mathrm{mg} / \mathrm{kg}$ ) and xylazine $(12 \mathrm{mg} / \mathrm{kg})$, followed by cervical dislocation. Hearts were excised, minced, and digested with collagenase type $4(100 \mathrm{U} / \mathrm{ml})$ and trypsin $(0.6 \mathrm{mg} / \mathrm{ml})$ at $37^{\circ} \mathrm{C}$ for $30 \mathrm{~min}$. The digestion was repeated for $3-5$ times. Isolated CFs were plated in laminin-coated $100 \mathrm{~mm}$ dishes (BD Biocoat ${ }^{\mathrm{TM}}$, BD Bioscience) and grown in 10\% FBS-DMEM medium. First passage CFs were used for experiments. For RNAi experiments, three lentiviral vectors encoding shRNA against Smad2, Smad3, mSin3A or control shRNA, respectively, were purchased from Santa Cruz Biotech Inc. Primary cultured CFs were transduced with these lentiviral vectors at a 


\section{Cellular Physiology Cell Physiol Biochem 2016;40:908-920 \begin{tabular}{l|l|l} 
and Biochemistry & DOI: 10.1159/000453149 & $\begin{array}{l}\text { (c) } 2016 \text { The Author(s). Published by S. Karger AG, Basel } \\
\text { www.karger.com/cpb }\end{array}$
\end{tabular} \\ Gong et al.: mSin3A-HDAC1-Smad3 Mediates PPAR $\gamma$ Inhibition by TGF- $\beta$}

Table 1. Primers for amplification of the deletions of hPPARg promoter

\begin{tabular}{ll}
\hline Primer name & Primer sequences \\
\hline A-2237F & 5'-TGGCGAGCTCTGGATGAGCCTCACAAATACT-3' \\
B-1737F & 5'-TAACGAGCTCCCCAAAGTGCTGGGATTACAGG-3' \\
C-1237F & 5'-AATAACGAGCTCCACGGAGCACTTCCGCCTGA-3' \\
D-750F & 5'-CGTCGAGCTCGGAAAAGAAAAGGTCACTGTC-3' \\
E-500F & 5'-GGTATCGAGCTCACCAAGGGACCCGAAATATG-3' \\
62R & 5'-TGTATGATAGGCTCGAGGCCGACCCAAGCG-3' \\
\hline
\end{tabular}

multiplicity of infection of 1 in 10\% FSB-DMEM containing $8 \mu \mathrm{g} / \mathrm{ml}$ of polybrene. After $48 \mathrm{~h}$, the culture media were replaced and CFs was starved for $24 \mathrm{~h}$ and then treated with vehicle or TGF- $\beta 1$. The protocols were approved by the Institutional Animal Care and Use Committee at the affiliated hospital of Yangzhou University and were consistent with the Guide for the Care and Use of Laboratory Animals published by the US National Institutes of Health (NIH Publication, 8th Edition, 2011).

Promoter deletion analysis

To define the sites of Smad binding elements (SBE) on the promoter of the PPAR $\gamma$ gene, deletions of human PPAR $\gamma$ promoter were constructend by PCR amplification using five pairs of primers, A-2237F/62R, B-1737F/62R, C-1237F/62R, D-750F/62R and E-500F/62R (Table 1), respectively. The promoter products were digested by Sac I and Xho I restriction endonucleases, and the hPPAR $\gamma$ promoter of the pGL3-luc vector was replaced by the above deletion fragments. The putative Smad binding sites (SBEs) were mutated using a QuickChange site-directed Mutagenesis Kit (Stratagene) according to the manufacturer's instructions. The primer used in site-directed mutation for $1507 \mathrm{~m}$ : F: 5'-TTT AAT TGT TTA GTA GAG ACT GTA TAT TGA CAT GTT GCC TAG ACT AGT CTG-3', R: 5'-CAG ACT AGT CTA GGC AAC ATG TCA ATA TAC AGT CTC TAC TAA ACA ATT AAA-3'; 1524m: 5' GAC ATG TTG CCT ATA TTA GTC TGA AAC TCC TGG GCT CAA G 3', R: 5' CTT GAG CCC AGG AGT TTC AGA CTA ATA TAG GCA ACA TGT C 3'. All constructs were confirmed by sequencing.

PPARy promoter activity analysis

Quiescent CFs were transiently co-transfected with a pGL3-Luc-hPPAR $\gamma$ promoter or truncated hPPAR $\gamma$ promoter plasmid, a pRL-TK plasmid and various expression plasmids including pRK5F-Smad2, -Smad3, -Smad4 or a mutant Smad3, pRK Smad3 deltaC Flag (Dn-Smad3) using the Lipofectamine Plus Transfection Reagent (Invitrogen). The plasmids have previously been described [13-15]. Cells transfected with empty vectors were used as controls. One day after transfection, CFs were treated with TGF- $\beta 1$ ( $4 \mathrm{ng} / \mathrm{ml}$, Sigma Aldrich) or vehicle for $12 \mathrm{~h}$, then harvested and lysed. Luminescence from transfected CFs was quantified by measuring firefly/Renilla luciferase activity using the Dual-Luciferase Reporter Assay System (Promega).

Chromatin immunoprecipitation (ChIP) analysis

ChIP assays were performed as previously described [11]. Briefly, quiescent CFs were treated with TGF- $\beta 1$ (4 ng/ml) or vehicle. After $1 \mathrm{~h}$, cells were fixed and nuclear protein-DNA complexes were extracted and subjected to ChIP analysis using anti-Smad2/3 (sc-8332, Santa Cruz), anti-Smad4 (sc-7154, Santa Cruz), anti-HDAC1 (sc-7872, Santa Cruz), anti-SNIP-1 (sc-134021, Santa Cruz) , anti-SIP-1(sc-48789, Santa Cruz), anti-TGIF(sc-17800 X, Santa Cruz), anti-Evi-1(sc-8706, Santa Cruz), anti-mSin3A (ab3479, Abcam) antibodies and rabbit IgG (sc-2027, Santa Cruz). A pair of primers (5'-ACA TCG GTC TGA GGG ACA CGG-G-3' and 5'-TAC CTG GCC GCC TTG CTC CT-3') were used to amplify a 72-bp fragment of the promoter region of the mouse PPAR $\gamma$ gene for detection of binding of various transcription factors. PCR was run at 29 to 31 cycles, and the PCR products were electrophoresed on agarose gels. To further quantitatate transcription factor binding to the PPAR $\gamma$ promoter, DNA content was measured by real-time RT-PCR with SYBR green reagent using an ABI PRISM 7500 sequence detection system (Applied Biosystems, Foster City, CA). For analysis, a ${ }^{\Delta} \mathrm{Ct}$ value was calculated for each sample: ${ }^{\Delta} \mathrm{Ct}=\mathrm{Ct}$ (sample)-Ct (Input). Next, a ${ }^{\Delta \Delta} \mathrm{Ct}$ value was calculated: ${ }^{\Delta \Delta} \mathrm{Ct}$ $=^{\Delta} \mathrm{Ct}$ (sample immunoprecipitated with various antibodies) $-^{-} \mathrm{Ct}$ (sample immunoprecipitated with IgG). The fold difference between the specific transcription factor antibody-immunoprecipitated samples and those immunoprecipitated with IgG was calculated using $2^{-\Delta \Delta C t}$. 


\section{Cellular Physiology Cell Physiol Biochem 2016;40:908-920

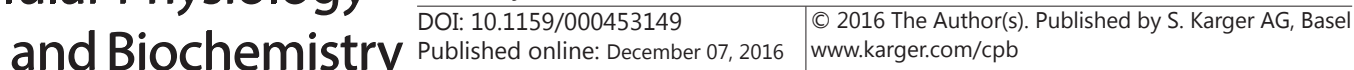 \\ Gong et al.: mSin3A-HDAC1-Smad3 Mediates PPAR $\gamma$ Inhibition by TGF- $\beta$}

DNA-affinity precipitation (DNAP)

Cell lysates were prepared in $150 \mathrm{mM} \mathrm{NaCl}, 1 \%$ Nonidet P-40, $20 \mathrm{mM}$ Tris-HCl (pH 7.5), $1 \mathrm{mM}$ PMSF and $20 \mu \mathrm{g} / \mathrm{ml}$ Aprotinin. Protein concentration was determined by a Bradford-based method (Bio-Rad). DNAP analysis was performed as previously described [16]. Briefly, equal amounts of proteins were precleared with streptavidin-agarose beads (Sigma) at $4{ }^{\circ} \mathrm{C}$ for $2 \mathrm{~h}$ and then incubated with $200 \mathrm{ng}$ of biotinylated double-stranded oligonucleotides in the presence of $2 \mu \mathrm{g}$ of poly ( $\mathrm{dI}-\mathrm{dC}$ ) at $4^{\circ} \mathrm{C}$ for $1 \mathrm{~h}$. DNAbound proteins were mixed with streptavidin-agarose for $1 \mathrm{~h}$ at $4^{\circ} \mathrm{C}$ for $1 \mathrm{~h}$. Proteins bound on streptavidinagar were washed with cell lysis buffer, centrifuged and resuspended in SDS loading buffer. Bound proteins were resolved by 7.5\% SDS-PAGE and detected by immunoblotting. Each experiment was repeated at least 3 times. The SBE (i.e. $3 \times$ CAGA) probe ( $5^{\prime}$-TCG AGA GCC AGA CAA GGA GCC AGA CAA GGA GCC AGA CAC TCG AG- $3^{\prime}$ ), described previously, was biotinylated at the $5^{\prime}$-end.

Western blotting analysis

Protein samples extracted from left ventricles or cultured CFs were separated by 10\% SDS-PAGE and transferred to polyvinylidene difluoride membrane as described previously [11]. Blots were probed with anti-PPAR $\gamma$ (Millipore-Upstate), anti-HDAC1(Santa Cruz), anti-mSin3A (Abcam), anti-pSmad3 (Cell Signaling Tech) and anti-GAPDH primary antibodies (Santa Cruz Biotech) and a horseradish peroxidaseconjugated secondary antibody, respectively. Bands were visualized by use of a Super Western Sensitivity Chemiluminescence Detection System (Pierce). Autoradiographs were quantitated by densitometry (NIH Image J).

Quantitative real-time RT-PCR analysis

Total RNA was extracted from CFs using TRIzol reagent (Invitrogen) and reverse transcribed to cDNA. cDNA was amplified by real-time quantitative PCR using the SYBR Green RT-PCR kit (Applied Biosystems) in an ABI PRISM 7500 sequence detection system (Applied Biosystems, Foster City, CA) with specific primers for mouse (PPARy: 5'-GAT GGA AGA CCA CTC GCA TT-3' and 5'-AAC CAT TGG GTC AGC TCT TG-3'; or GAPDH: 5'-GTT GTC TCC TGC GAC TTC A-3' and 5'-GTG GTC CAG GGT TTC TTA CT-3') as described previously [11]. PPAR $\gamma$ mRNA levels were normalized using GAPDH mRNA and then standardized to the mRNA level of vehicle-treated CFs.

\section{Statistical analysis}

Results were expressed as mean \pm SEM. Analyses were carried out the SPSS software version 11.0 for Windows (SPSS Inc., Chicago, Ill). Our primary statistical test was One-way or Two-way ANOVA. If ANOVA results were significant, a Bonferroni post hoc comparison, when appropriate, was performed. Paired samples were tested with a Student T test. A P value $<0.05$ was considered statistically significant.

\section{Results}

Over-expression of Smad3 and Smad4 but not Smad2, enhances TGF- $\beta 1$-induced inhibition of PPAR $\gamma$ promoter activity in CFS

Previously, we utilized a non-specific antibody against both Smad2 and Smad3 to confirm that these Smad proteins bind to the PPAR $\gamma$ promoter in response to TGF- $\beta 1$ stimulation in mouse CFs using ChIP analysis. To further define which Smad protein is involved in TGF- $\beta 1$-induced inhibition of PPAR $\gamma$ transcription, isolated CFs were transiently co-transfected with the various Smad plasmids with a Luc-hPPAR $\gamma$ promoter plasmid. After $24 \mathrm{~h}$ of transfection, CFs were treated with $4 \mathrm{ng} / \mathrm{ml}$ TGF- $\beta 1$ for $12 \mathrm{~h}$. The Dual-luciferase reporter assay showed that over-expression of Smad3 or Smad4 significantly enhanced TGF- $\beta 1$-induced inhibition of PPAR $\gamma$ promoter activity (Fig. 1A,B). In contrast, Smad 2 overexpression did not affect PPAR $\gamma$ promoter activity in response to TGF- $\beta 1$ (Fig. $1 \mathrm{C}$ ). Combined transfection of Smad3 and Smad4 further enhanced the suppression of PPAR $\gamma$ promoter activity by TGF- $\beta 1$ compared with either Smad3 or Smad4 alone (Fig. 1D). To further determine the role of Smad3 in mediating the inhibitory effect of TGF- $\beta 1$ on PPAR $\gamma$ promoter activity, we transfected a dominant-negative form of the Smad3 plasmid. As shown in Fig 
Fig. 1. The effects of Smads in TGF- $\beta 1$-induced inhibition of PPAR $\gamma$ promoter activity. CFs were transiently co-transfected various plasmids, including empty vector (control), $100 \mathrm{ng}$ to $1 \mathrm{ug} \mathrm{Smad} 3$ (A), Smad4 (B), Smad2(C), 1ug Smad3 or Smad4 or both (D) and 1ug mutant Smad3 (E) with a Luc-hP$\mathrm{PAR} \gamma$ promoter plasmid. After 24 $\mathrm{h}$, cells were treated with $4 \mathrm{ng} / \mathrm{ml}$ TGF- $\beta 1$ or vehicle for $12 \mathrm{~h}$. Promoter activity was measured with a Dual-Luciferase reporter assay system. The results are expressed as mean \pm SEM, $n=6,{ }^{*} \mathrm{p}<0.05$ vs vehicle, ${ }^{*} \mathrm{p}<0.05$ vs empty vector, $\Delta \mathrm{p}<0.05$ vs 100 ng Smad3, $\mathrm{p}<0.05$ vs Smad3 alone. (F) CFs were infected with lenti-virus carrying Smad2, Smad3 or control shRNA for $72 \mathrm{~h}$ and then treated with $4 \mathrm{ng}$ / $\mathrm{ml}$ TGF- $\beta 1$ or vehicle for $24 \mathrm{~h}$. The level of PPAR $\gamma$ mRNA expression was determined by real time RTPCR analysis( $\mathrm{n}=6),{ }^{*} \mathrm{p}<0.05$ compared with control shRNA; ${ }^{*} \mathrm{P}<0.05$ vs vehicle.
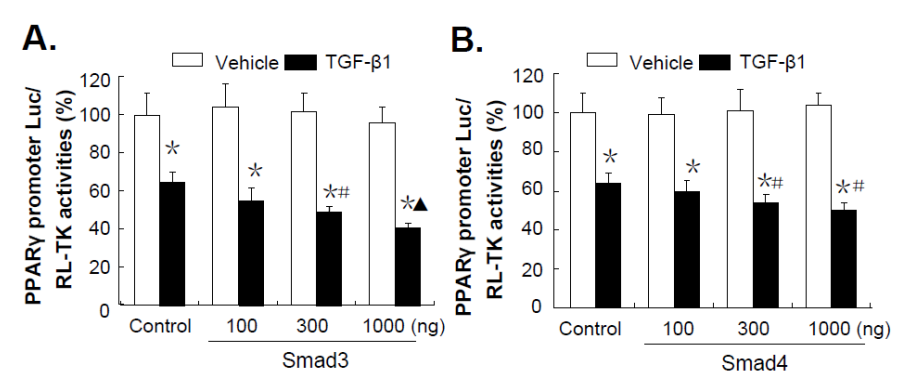

C.

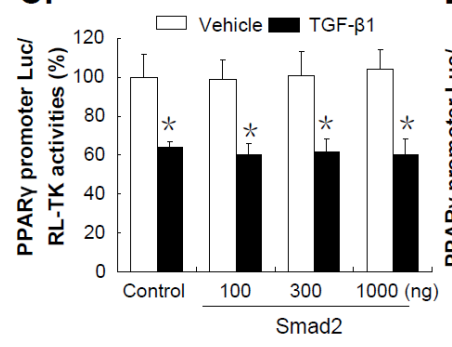

D.
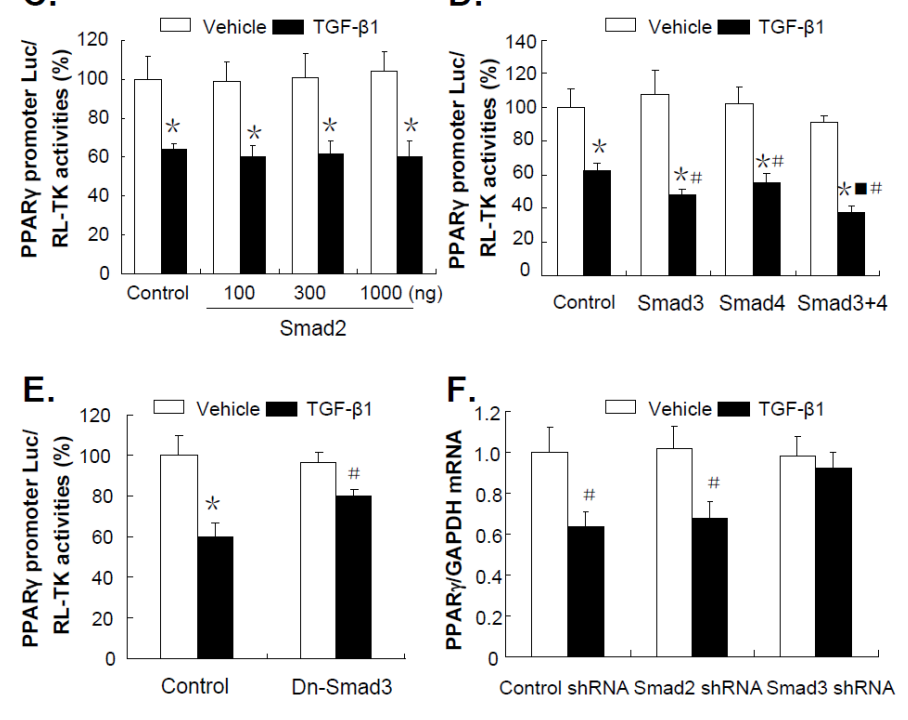

1E, over-expression of the mutant Smad3 significantly attenuated the inhibitory effect of TGF- $\beta 1$. Consistently, transfection with lentivirus-encoding Smad3 shRNA, but not Smad2 shRNA, significantly attenuated TGF- $\beta 1$-induced PPAR $\gamma$ mRNA down-regulation compared with the control shRNA (Fig 1F). These results indicate that receptor-activated Smad3, but not Smad2, mediates TGF- $\beta 1$-induced transcriptional suppression of PPAR $\gamma$.

\section{Location of Smad3 binding sites on the promoter of the PPAR $\gamma$ gene}

To further elucidate the sites of SBEs on the promoter of the PPAR $\gamma$ gene, serial deletions of the PPAR $\gamma$ promoter reporter were constructed and transiently transfected into cultured CFs (Fig. 2A). Cells were treated with TGF- $\beta 1$ for $12 \mathrm{~h}$ and the Dual-luciferase reporter assay was carried out. Compared with the full-length PPAR $\gamma$ gene promoter, deletion of the first $500 \mathrm{bp}$ fragment (A-2237) from -2737 to -2237 with respect to the transcription start site resulted in significantly decreased basal promoter activity, suggesting that transcriptional enhancers in the region played a role in maintenance of basal PPAR $\gamma$ gene promoter activity. The inhibitory effect of TGF- $\beta 1$ on the truncated PPAR $\gamma$ gene promoter (i.e. A-2237) was preserved. Deletion of the region from -2237 to -1737 resulted in a significant increase in basal promoter activity of A-2237, and TGF- $\beta 1$ treatment suppressed the transcriptional activity of the truncated promoter. In contrast, when the region from -1737 and -1237 was deleted (C-1237), basal transcriptional activity remained unchanged, but the inhibitory effect of TGF- $\beta 1$ on promoter activity was abolished. Similarly, TGF- $\beta 1$ treatment had no effect on the promoter activities of D-750 or E-500(Fig. 2B). Based on these results, two putative SBE sites (GTCT and AGAC) in the region from -1737 to -1237 with respect to the transcription start site were further examined by site-directed mutation methods. As shown in Fig. 2C, 
Fig. 2. Mapping the SBEs on the promoter of PPAR $\gamma$ gene. A) A schematic structure of serial deletions of the PPAR $\gamma$ gene promoter generated by PCR; B) Truncated PPAR $\gamma$ gene reporter analysis. CFs were transiently co-transfected with the truncated PPAR $\gamma$ gene reporter and a RL-TK plasmid. After $24 \mathrm{~h}$, cells were treated with $4 \mathrm{ng} /$ $\mathrm{ml}$ TGF- $\beta 1$ or vehicle for 12 h. Promoter activity was measured with a Dual-Luciferase reporter assay system. ${ }^{*} \mathrm{p}<0.05$ vs vehicle, ${ }^{\#} \mathrm{p}<0.05$ vs A-2237. C) Effect of SBE mutation on TGF- $\beta 1$-induced transcriptional inhibition of PPAR $\gamma$. $-1507 \mathrm{~m}$ : the B-1737 reporter with a mutation at
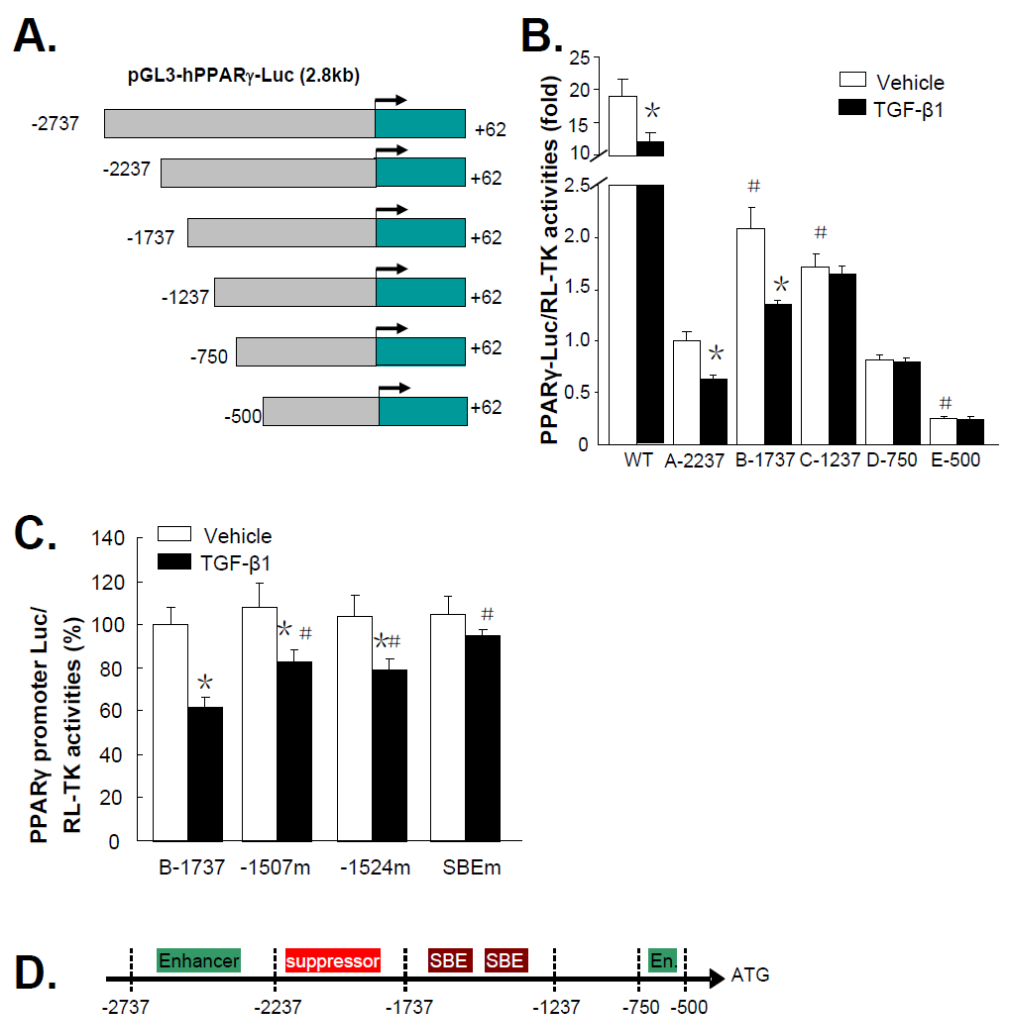

site -1507; -1524m: the B-1737 reporter with a mutation at site -1524; SBEm: the B-1737 reporter with two mutations at site -1507 and -1524 . B-1737 and mutants were transiently co-transfected with RL-TK plasmid into CFs and then treated with TGF- $\beta 1$ or vehicle. Reporter activities were measured. ${ }^{*} \mathrm{p}<0.05$ vs vehicle, ${ }^{\#} \mathrm{p}<0.05$ vs B-1737. Results are expressed as mean \pm SEM, $n=6$. D) Schematic structure of the PPAR $\gamma$ gene promoter labeled with functional regulatory elements.

compared with their parent reporter B-1737, both the -1507 (AGAC $\rightarrow$ AtAt, $-1507 m$ ) and -1524 mutations (GTCT $\rightarrow$ aTaT, $-1524 \mathrm{~m}$ ) resulted in significant decreases in TGF- $\beta 1$-induced inhibition of promoter activity. Further, the combination of -1507 and -1524 mutations (SBEm) led to complete loss of the TGF- $\beta 1$-induced inhibitory effect. A schematic structure of the PPAR $\gamma$ gene is presented is Fig. 2D.

mSin3A binding to the promoter of the PPAR $\gamma$ gene in response to TGF- $\beta 1$ stimulation in cultured CFS

To define which co-repressors are involved in TGF- $\beta$-induced PPAR $\gamma$ gene repression, we used ChIP assays to screen several common TGF- $\beta$ signaling-related transcriptional corepressors, including Evi-1, mSin3A, TGIF, SNIP-1 and SIP-1. In cultured CFs, ChIP assays showed that in the absence of TGF- $\beta 1$, moderate levels of Smad3 and low levels of HDAC1 and $\mathrm{mSin} 3 \mathrm{~A}$ were present at the PPAR $\gamma$ promoter. In contrast, SNIP-1, SIP-1, TGIF and Evi-1 did not bind to the PPAR $\gamma$ promoter in the presence of TGF- $\beta 1$. However, TGF- $\beta 1$ treatment enhanced the levels of Smad3 and the transcriptional co-repressors mSin3A and HDAC1 at the promoter region of the PPAR $\gamma$ gene compared with vehicle (Fig. 3).

Smad3-mSin3A-HDAC1 complex formation at the promoter of the PPAR $\gamma$ gene in response to TGF- $\beta 1$

To further elucidate the molecular events at the PPAR $\gamma$ promoter, we used the DNAaffinity precipitation assay to examine the interaction among these molecules. Biotin-labeled 


\section{Cellular Physiology Cell Physiol Biochem 2016;40:908-920 \begin{tabular}{l|l|l} 
and Biochemistry $10.1159 / 000453149$ & (c) 2016 The Author(s). Published by S. Karger AG, Basel \\
www.kargercom/cpb
\end{tabular}

Fig. 3. TGF- $\beta 1$ treatment increased binding of the transcriptional repressor mSin3A to the PPAR $\gamma$ gene promoter in cultured CFs. CFs were treated with TGF- $\beta 1(4 \mathrm{ng} / \mathrm{ml})$ or vehicle for $1 \mathrm{~h}$. Levels of SNIP1, SIP1, TGIF, Evi-1, Smad3, mSin3A and HDAC1 bound to the PPAR $\gamma$ promoter were determined by ChIP assay. A representative set of results from at least 3 independent assays is shown. ${ }^{*} \mathrm{p}<0.05$ compared with respective vehicle control groups.

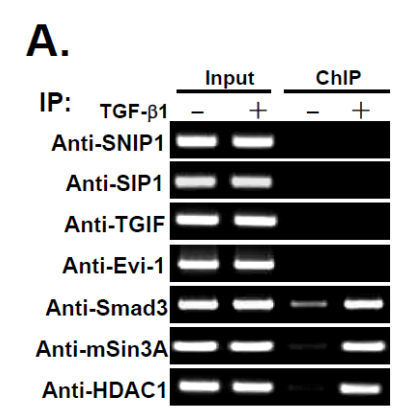

B.

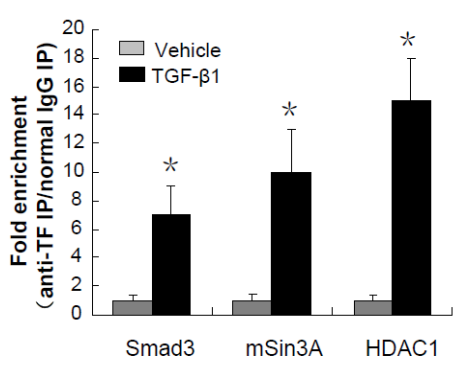

Fig. 4. TGF- $\beta 1$ treatment enhanced the binding of pSmad3, mSin3A and HDAC1 to the PPAR $\gamma$ gene promoter in cultured CFs. CFs were treated with TGF- $\beta 1$ ( $4 \mathrm{ng} / \mathrm{ml}$ ) or vehicle for $1 \mathrm{~h}$. Equal amounts of proteins were precleared with streptavidin-agarose beads and then incubated with 200 ng of biotinylated double-stranded $3 \times$ CAGA probe and streptavidin-agarose. The DNA-bound proteins were resolved by $7.5 \%$ SDS-PAGE and detected by immunoblotting with anti-pSmad3, anti-mSin3A and anti-HDAC1. Each experiment was repeated at least 3 times.

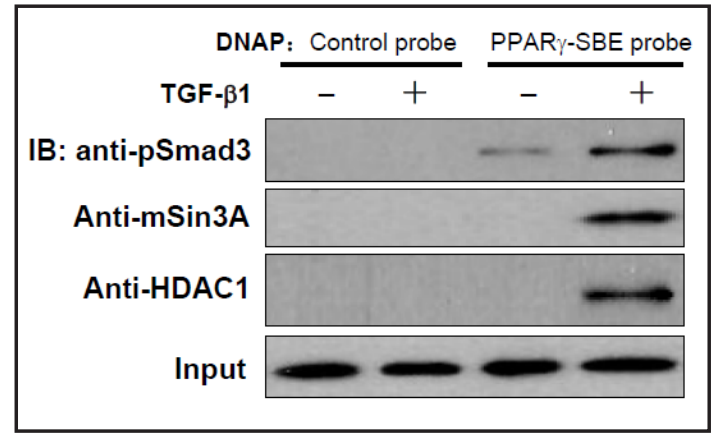

oligomers consisting of SBE repeats were incubated with the protein extracts of untreated or TGF- $\beta 1$ treated CFs. Low levels of phosphorylated smad3 bound to DNA in extracts of unstimulated cells, while TGF- $\beta 1$ treatment enhanced Smad3 binding to the PPAR $\gamma$ promoter, and $\mathrm{mSin} 3 \mathrm{~A}$ and HDAC1 binding were also increased in the SBE probe-treated precipitants (Fig. 4). There results provide evidence that activation of TGF- $\beta 1$ signaling favors the formation of a transcription complex comprising Smad3, mSin3A and HDAC1 at the PPAR $\gamma$ promoter.

Silencing mSin3A and inhibiting HDAC1 attenuate TGF- $\beta 1$-induced inhibition of PPAR $\gamma$ down-regulation

To further define the roles of mSin3A and HDAC1 in TGF- $\beta 1$-induced inhibition of PPAR $\gamma$ gene transcription, isolated CFs were transfected with lentivirus-encoding shRNA against mouse mSin $3 \mathrm{~A}$. Immunoblot assays showed that transfection of mSin3A shRNA dramatically decreased endogenous mSin $3 A$ expression compared with control shRNA. As expected, silencing mSin3A markedly attenuated TGF- $\beta 1$-induced PPAR $\gamma$ down-regulation compared with the control shRNA (Fig. 5A-C). Further, pretreatment with MS-275, a selective antagonist of HDAC1, significantly increased PPAR $\gamma$ expression in the presence of TGF- $\beta 1$ compared with vehicle (Fig. 5D).

Silencing mSin3A decreases TGF- $\beta 1$-induced HDAC1 binding to the promoter of PPAR $\gamma$

We have previously demonstrated that in the absence of TGF- $\beta 1$, high levels of acetylated histone 3 were present at the PPAR $\gamma$ promoter. While TGF- $\beta 1$ treatment significantly increased binding of HDAC1, it decreased levels of acetylated histone 3 at the PPAR $\gamma$ promoter in isolated CFs [11]. In CFs transfected with mSin3A shRNA, ChIP assays showed that silencing mSin3A expression completely prevented HDAC1 binding to the PPAR $\gamma$ promoter in the presence of TGF- $\beta 1$ (Fig. 6). These results suggest that, with the help of HDAC1, the PPAR $\gamma$ gene transcription was significantly inhibited in the presence of TGF- $\beta 1$ and that mSin $3 \mathrm{~A}$ 
Fig. 5. The effects of $\mathrm{mSin} 3 \mathrm{~A}$ and HDAC 1 on TGF- $\beta 1$-induced inhibition of PPAR $\gamma$. (A-C) CFs were infected with lenti-virus carrying mSin3A shRNA or control shRNA for $72 \mathrm{~h}$ and then treated with $4 \mathrm{ng} /$ $\mathrm{ml}$ TGF- $\beta 1$ or vehicle for $24 \mathrm{~h}$. The $\mathrm{mSin} 3 \mathrm{~A}$ and PPAR $\gamma$ protein levels were determined by western blot analysis. $\mathrm{n}=4, * \mathrm{p}<0.05$ compared with vehicle; ${ }^{*} \mathrm{P}<0.05$ vs control shRNA. (D) CFs were pretreated with vehicle or MS-275 for $1 \mathrm{~h}$ and then exposed to TGF- $\beta 1$ for $24 \mathrm{~h}$. The PPAR $\gamma$ mRNA level was measured by real-time RT-PCR. $n=6$, ${ }^{*} \mathrm{P}<0.05$ vs Vehicle; ${ }^{*} \mathrm{P}<0.05$ vs con-

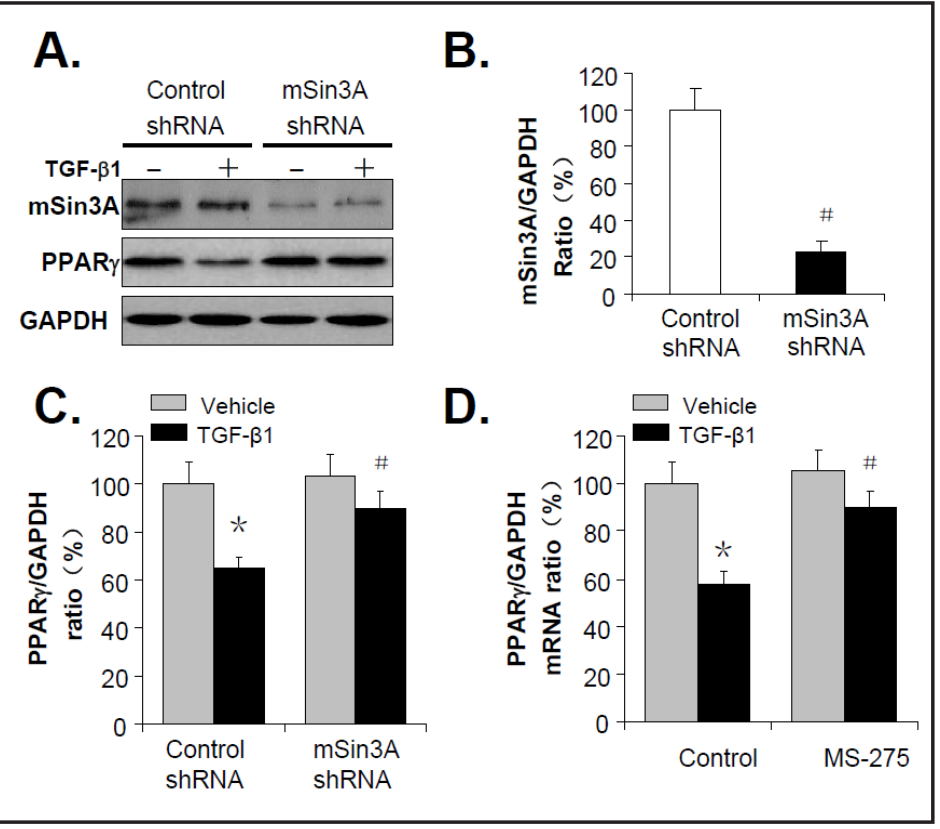

Fig. 6. Silencing $m$ Sin $3 A$ attenuated HDAC1 binding to the PPAR $\gamma$ gene promoter in response to TGF- $\beta 1$ in cultured CFs. CFs were infected with lenti-virus carrying mSin3A shRNA or control shRNA for $72 \mathrm{~h}$ and then treated with $4 \mathrm{ng} / \mathrm{ml}$ TGF- $\beta 1$ or vehicle for $24 \mathrm{~h}$. The HDAC1 binding level at the PPAR $\gamma$ promoter was determined by ChIP assay. A representative set of results from at least 3 independent assays is shown. ${ }^{*} \mathrm{p}<0.05$ compared with vehicle.

A.

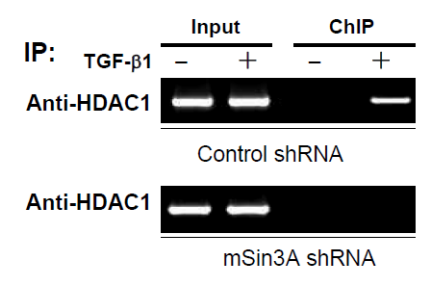

B.

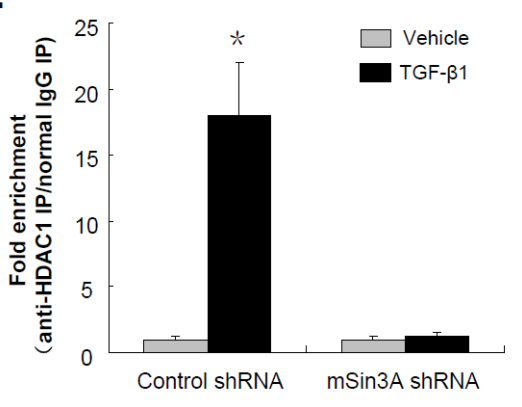

plays an essential role in HDAC1-mediated transcriptional inhibition of the PPAR $\gamma$ gene in response to TGF- $\beta 1$.

\section{Discussion}

The current study has demonstrated that: 1) Smad3 acts as a key transcription factor to mediate TGF- $\beta 1$-induced down-regulation of PPAR $\gamma$ in mouse CFs; 2 ) Two SBEs located at -1507 and -1524 with respect to the transcription start site are required for TGF- $\beta 1$-induced transcriptional suppression of PPAR $\gamma$; 3) Formation of the mSin3A-HDAC1-Smad3 complex on the promoter of PPAR $\gamma$ in response to TGF- $\beta 1$ stimulation leads to transcriptional suppression of the PPAR $\gamma$ gene.

PPAR- $\gamma$ has long been thought to function as a master regulator of glucose homeostasis and fat metabolism and is now emerging as a key regulatory molecule in fibrosis and vascular remodeling [16-19]. Evidence is accumulating that, on one hand, there is a causal 
relationship between fibrosis and defective PPAR $\gamma$ expression and function and, on the other hand, pharmacological enhancement of PPAR $\gamma$ tissue levels and activity using PPAR $\gamma$ ligands or proteasomal inhibitors can effectively prevent, and perhaps even reverse, fibrosis and vascular remodeling [16]. For example, cardiomyocyte-specific PPAR $\gamma$ knockout mice have been shown to develop age-dependent cardiac hypertrophy [5], and the decrease in myocardial PPAR $\gamma$ in these mice is associated with increasing severity of cardiac pathology in response to stress [20].

Mice harboring a dominant-negative PPAR $\gamma$ mutation develop exaggerated cardiac fibrosis when challenged with angiotensin II [21]. We previously reported that disruption of TGF- $\beta$ signaling by inducible over-expression of a dominant negative type II TGF- $\beta$ receptor effectively prevented chronic pressure overload-induced down-regulation of myocardial PPAR $\gamma$ in mouse, whereas inhibition of PPAR $\gamma$ with T0070907 exacerbated and activation of PPAR $\gamma$ by rosiglitazone dramatically inhibited cardiac fibrosis in response to transverse aortic constriction [11]. Further, in isolated mouse CFs, TGF- $\beta 1$ suppressed expression of PPAR $\gamma$ at the protein and mRNA levels.

However, the molecular events in the nucleus that underlie TGF- $\beta$-induced PPAR $\gamma$ transcriptional inhibition are poorly understood. Previous studies have shown that several families of transcription factors are responsible for the regulation of PPAR $\gamma$ transcription [22]. For example, constitutive expression of GATA-2 and GATA-3 can decrease PPAR $\gamma$ expression and thus inhibit adipocyte differentiation [23, 24]. Also, E2F4, when associated with p107 or p130, was implicated in repression of PPAR $\gamma$ expression during terminal adipocyte differentiation [25]. It remains unclear whether the canonical Smad2/3 pathway or a non-smad pathway orchestrates TGF- $\beta$-induced PPAR $\gamma$ transcriptional inhibition in mouse CFs.

It is clear that receptor activated Smad2 and Smad3 can bind to co-Smad, i.e. Smad4 to form a heteromeric complex and translocate into the nucleus to either promote or block target gene transcription. Although Smad3 and Smad2 share some structural characteristics, they clearly have important functional and structural differences [26, 27]. For example, the MH1 domains of Smad3 and Smad2 have different DNA binding ability and binding sites. In contrast to Smad2, which activates the TGF- $\beta$ /activin response element, Smad3 elicits an antagonistic activity conferred by the MH1 domain. Here, we showed that transient overexpression of Smad3, but not Smad2, effectively enhanced the inhibitory effects of TGF- $\beta 1$ on PPAR $\gamma$ promoter activity, providing further evidence for functional differences between Smad2 and Smad3. Labbe et al tested the effects of Smad 2 and Smad3 on response elements of several gene promoters, including the goosecoid $(g s c)$ promoters, the activin response element in the Mix.2 gene and 3TP-luc [28]. They found that Smad3 inhibited, and, Smad2 enhanced the activities of the first two response elements, but that Smad2 and Smad3 enhanced the activity of 3TP in a synergistic manner. These results demonstrate a genespecific effect of Smad3 and Smad2 on transcriptional regulation.

Our findings that both Smad3 and Smad4, but not Smad2, mediated TGF- $\beta$-induced PPAR $\gamma$ transcriptional inhibition in mouse CFs are consistent with a previous study in rat hepatic stellate cells [29]. Further, functional deletion promoter analysis showed that deletion in the region from -2737 to -2237 resulted in a dramatic decrease in basal promoter activity of the PPAR $\gamma$ gene. In contrast, deletion in the region from -2237 and -1737 caused a significant increase in promoter activity of the PPAR $\gamma$ gene. There results suggest that a key transcriptional enhancer and suppressor are located in the two regions. Future work is needed to identify these key transcriptional regulatory factors. Interestingly, we found that only the fragment between -1737 and -1237 played a critical role in TGF- $\beta$-induced transcriptional inhibition of PPAR $\gamma$, since deletion of the region fully abolished the effect of TGF- $\beta$ on the PPAR $\gamma$ promoter. Further, site-directed mutagenesis assays showed that two SBEs are located at $-1507 \mathrm{bp}$ and $-1524 \mathrm{bp}$ with respect to the transcriptional start site of the PPAR $\gamma$ gene.

Smad transcription complexes target specific genes for either induction or inhibition through the direct recruitment of transcriptional coactivators or corepressors to target 
promoters. Other modalities, including Smad interference with activators or repressors, and Smad cooperation with DNA, play a role in target gene regulation [30]. For example, activated Smad2/3-Smad4 complexes achieve high affinity and selectivity for target gene promoters by associating with diverse DNA-binding factors. Therefore, in most cases the Smad-interacting transcriptional co-factors and DNA-binding partners play important roles in the specific transcriptional effects (i.e activation or repression) that are exerted on a target gene.

Several Smad2, 3 transcriptional co-repressors and DNA-binding partners have been identified, including TGIF, Evi-1, SIP-1, c-Ski and mSin3 [31, 32]. For example, TGIF interacts specifically with Smad2 and Smad3 and recruits a complex of general corepressors such as C-terminal-binding protein 1(CtBP) [33]. Further, binding of TGIF prevents the interaction of Smads with co coactivators to repress the activation of target gene expression. The protooncoprotein Ski and the related protein SnoN act as the co-repressors of Smad3, where Ski prevents the formation of an activated Smad2,3 complex [34] and competes with p300 for binding to Smad3 on the target gene promoter [35], and finally antagonizes the growth inhibitory response of epithelial cells to TGF- $\beta$ [36]. Evi-1, a zinc finger containing protooncoprotein, was shown to bind to Smad3 and corepressor protein CtBP and inhibit Smad3 binding to DNA, thus exerting full repression of the TGF- $\beta$ response [37].

Chromatin plays an important role in the regulation of gene transcription, replication and recombination by controlling the access of regulatory proteins to the DNA [38]. Acetylation of core histones relaxes the nucleosome and permits transcription factors and coactivators to gain access to recognition elements and initiate transcription. Corepressors mediate transcriptional suppression through binding with HDACs, which deacetylate core histones and generate a restrictive chromatin environment to prevent the transcription machinery from binding to the promoter DNA [39]. To determine which co-repressor was involved in HDAC1-related transcriptional inhibition of PPAR $\gamma$ in the presence of TGF- $\beta 1$, we screened the potential transcriptional co-repressors using ChIP analysis. We observed that, in response to TGF- $\beta 1$, HDAC 1 and $\mathrm{mSin} 3 \mathrm{~A}$ binding to the PPAR $\gamma$ promoter was significantly increased. The DNA-affinity precipitation assay also showed that TGF- $\beta 1$ treatment potentiated mSin $3 \mathrm{~A}$ and HDAC1 binding to PPAR $\gamma$-SBE probe-labled cellular precipitants. Similarly, a previous study showed that p53 anchoring of activated Smads and mSin3A to the AFP promoter plays a critical role in TGF- $\beta$-induced transcriptional repression in hepatic cells [40]. Together, these results suggest that TGF- $\beta 1$-induced inhibition of PPAR $\gamma$ transcription depends on formation of a functional transcription complex at the PPAR $\gamma$ promoter that includes Smad3, mSin3A and HDAC1.

In mammals, Sin3 exists as two subtypes, $\mathrm{mSin} 3 \mathrm{~A}$ and $\mathrm{mSin} 3 \mathrm{~B}$, that share a similar scaffolding function for the assembly of the corepressor complex [41]. Previous studies demonstrated that the Sin3 corepressor complex serves as an HDAC-associated coregulator complex in negatively regulating promoter-dependent transcription, and is also implicated in the regulation of DNA and histone methylation, nucleosome remodeling, and $\mathrm{N}$-acetylglucosamine transferase activity [42]. HDACs have been shown to be recruited directly by Smads or by associated co-repressors on the target gene promoter [43]. Since Sin3 functions as a master scaffold to provide a platform for the assembly of transcriptional machinery [44], Sin3-mediated gene silencing is thought to be achieved primarily through scaffolding of core HDAC complexes [45]. Consistent with this concept, we found that knockdown of the mSin3A gene fully prevented TGF- $\beta 1$-induced HDAC1 binding to the PPAR $\gamma$ promoter, and that inhibition of HDAC1 with the specific blocker MS-275 also attenuated TGF$\beta 1$-induced down-regulation of PPAR $\gamma$ mRNA expression. Further, it has been shown that pharmacological inhibition of HDAC1 is associated with improvement in cardiac function via a direct anti-fibrotic effect in rats with heart failure [46]. We did not detect $\mathrm{mSin} 3 \mathrm{~B}$ binding to the PPAR $\gamma$ promoter in response to TGF- $\beta 1$ by ChIP analysis (unpublished data), suggesting that $\mathrm{mSin} 3 \mathrm{~B}$ is not likely to be involved in mediating TGF- $\beta 1$-induced down-regulation of PPAR $\gamma$ in CFs. Collectively, our results suggest that mSin3A plays an essential role in HDAC1mediated transcriptional inactivation of the PPAR $\gamma$ gene in response to TGF- $\beta 1$. 


\section{Cellular Physiology Cell Physiol Biochem 2016;40:908-920

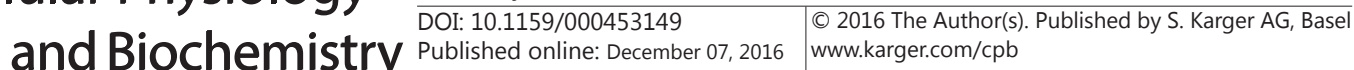 \\ Gong et al.: mSin3A-HDAC1-Smad3 Mediates PPAR $\gamma$ Inhibition by TGF- $\beta$}

In summary, we demonstrate here for the first time that upon TGF- $\beta 1$ stimulation, formation of a transcriptional repression complex that includes Smad3, Smad4, mSin3A and HDAC1 plays an essential role in the down-regulation of PPAR $\gamma$ in mouse CFs. The present study provides new insights into the molecular mechanisms underlying chronic pressure overload-induced cardiac fibrosis, a setting in which expression of the endogenous antifibrotic factor PPAR $\gamma$ is suppressed and TGF- $\beta 1 / \mathrm{Smad} 3$ signaling is highly activated.

\section{Acknowledgements}

This work was partly supported by the National Natural Science Foundation of China (81070096, 81270197, 81270198 and 81470381), the Natural Science Foundation of Jiangsu Province (BK2010324), the Project of Prospering Health by Science and Education in Jiangsu Province (RC2011045), Jiangsu Six-type Top Talent Funding (2014-WSN-077) and Jiangsu Key R\&D Project in Social Development (BE2015663).

\section{Disclosures Statement}

None of the authors has any conflicts of interest to disclose relevant to this work.

\section{References}

1 Qi HP, Wang Y, Zhang QH, Guo J, Li L, Cao YG, Li SZ, Li XL, Shi MM, Xu W, Li BY, Sun HL: Activation of peroxisome proliferator-activated receptor $\gamma$ (PPAR $\gamma$ ) through NF- $\kappa \mathrm{B} / \mathrm{Brg} 1$ and TGF- $\beta 1$ pathways attenuates cardiac remodeling in pressure-overloaded rat hearts. Cell Physiol Biochem 2015;35:899-912

2 Tao L, Bei Y, Lin S, Zhang H, Zhou Y, Jiang J, Chen P, Shen S, Xiao J, Li X: Exercise training protects against acute myocardial infarction via improving myocardial energy metabolism and mitochondrial biogenesis. Cell Physiol Biochem 2015;37:162-175.

3 Son NH, Park TS, Yamashita H, Yokoyama M, Huggins LA, Okajima K, Homma S, Szabolcs MJ, Huang LS, Goldberg IJ: Cardiomyocyte expression of PPAR $\gamma$ leads to cardiac dysfunction in mice. J Clin Invest 2007;117:2791-2801

4 Mehrabi MR, Haslmayer P, Humpeler S, Strauss-Blasche G, Marktl W, Tamaddon F, Serbecic N, Wieselthaler G, Thalhammer T, Glogar HD, Ekmekcioglu C: Quantitative analysis of peroxisome proliferator-activated receptor gamma (PPARgamma) expression in arteries and hearts of patients with ischaemic or dilated cardiomyopathy. Eur J Heart Fail 2003;5:733-739.

5 Duan SZ, Ivashchenko CY, Russell MW, Milstone DS, Mortensen RM: Cardiomyocyte-specific knockout and agonist of peroxisome proliferator-activated receptor- $\gamma$ both induce cardiac hypertrophy in mice. Circ Res 2005;97:372-379.

6 Hansmann G, de Jesus Perez VA, Alastalo TP, Alvira CM, Guignabert C, Bekker JM, Schellong S, Urashima T, Wang L, Morrell NW, Rabinovitch M: An antiproliferative BMP-2/PPARgamma/apoE axis in human and murine SMCs and its role in pulmonary hypertension. J Clin Invest 2008;118:1846-1857.

7 Zhao X, Wang K, Liao Y, Zeng Q Li Y, Hu F, Liu Y, Meng K, Qian C, Zhang Q, Guan H, Feng K, Zhou Y, Du Y, Chen Z: MicroRNA-101a inhibits cardiac fibrosis induced by hypoxia via targeting TGFßRI on cardiacfibroblasts. Cell Physiol Biochem 2015;35:213-226.

8 Dobaczewski M, Chen W, Frangogiannis NG. Transforming growth factor (TGF)- $\beta$ signaling in cardiac remodeling. J Mol Cell Cardiol 2011;51:600-606.

9 Samarakoon R, Overstreet JM, Higgins PJ. TGF- $\beta$ signaling in tissue fibrosis: redox controls, target genes and therapeutic opportunities. Cell Signal 2013;25:264-268.

10 Wang P, Yang AT, Cong M, Liu TH, Zhang D, Huang J, Tong XF, Zhu ST, Xu Y, Tang SZ, Wang BE, Ma H, Jia JD, You H: EGF Suppresses the Initiation and Drives the Reversion of TGF- $\beta 1$-induced Transition in Hepatic Oval Cells Showing the Plasticity of Progenitor Cells. J Cell Physiol 2015;230:2362-2370. 


\section{Cellular Physiology Cell Physiol Biochem 2016;40:908-920 \begin{tabular}{l|l|l|}
\hline DOI: 10.1159/000453149 & $\begin{array}{l}\text { C) 2016 The Author(s). Published by S. Karger AG, Basel } \\
\text { www.karger.com/cpb }\end{array}$ \\
\hline Published online:
\end{tabular} \\ Gong et al.: mSin3A-HDAC1-Smad3 Mediates PPAR $\gamma$ Inhibition by TGF- $\beta$}

11 Gong K, Chen YF, Li P, Lucas JA, Hage FG, Yang Q, Nozell SE, Oparil S, Xing D: Transforming growth factor- $\beta$ inhibits myocardial PPAR $\gamma$ expression in pressure overload-induced cardiac fibrosis and remodeling in mice. J Hypertens 2011;29:1810-1819.

12 Li P, Wang D, Lucas J, Oparil S, Xing D, Cao X, Novak L, Renfrow MB, Chen YF: ANP inhibits TGF-induced Smad signaling and myofibroblast transformation in mouse cardiac fibroblast. Circ Res 2008;102:185-192.

13 Sysa P, Potter JJ, Liu X, Mezey E. Transforming growth factor- $\beta 1$ up-regulation of human $\alpha 1$ (i) collagen is mediated by sp1 and smad2 transacting factor. DNA Cell Biol 2009;28:425-434.

14 Fajas L, Auboeuf D, Raspé E, Schoonjans K, Lefebvre AM, Saladin R, Najib J, Laville M, Fruchart JC, Deeb S, Vidal-Puig A, Flier J, Briggs MR, Staels B, Vidal H, Auwerx J. The organization, promoter analysis, and expression of the human PPARgamma gene. J Biol Chem 1997;272:18779-18789.

15 Blanquicett C, Kang BY, Ritzenthaler JD, Jones DP, Hart CM. Oxidative stress modulates PPAR gamma in vascular endothelial cells. Free Radic Biol Med 2010;48:1618-1625.

16 Wei J, Bhattacharyya S, Jain M, Varga J: Regulation of matrix remodeling by peroxisome proliferatoractivated receptor- $\gamma$ : a novel link between metabolism and fibrogenesis. Open Rheumatol J 2012;6:103115.

17 Choi S, Jung JE, Yang YR, Kim ES, Jang HJ, Kim EK, Kim IS, Lee JY, Kim JK, Seo JK, Kim JM, Park J, Suh PG, Choi JH: Novel phosphorylation of PPAR $\gamma$ ameliorates obesity-induced adipose tissue inflammation and improves insulin sensitivity. Cell Signal 2015;27:2488-2495.

$18 \mathrm{Xu}$ X, He M, Liu T, Zeng Y, Zhang W: Effect of salusin- $\beta$ on peroxisome proliferator-activated receptor gamma gene expression in vascular smooth muscle cells and its possible mechanism. Cell Physiol Biochem 2015;36:2466-2479

19 Yang D, Chen H, Zeng X, Xie P, Wang X, Liu C: Macrophage CGI-58 attenuates inflammatory responsiveness via promotion of PPAR $\gamma$ signaling. Cell Physiol Biochem 2016;38:696-713.

20 Caglayan E, Stauber B, Collins AR, Lyon CJ, Yin F, Liu J, Rosenkranz S, Erdmann E, Peterson LE, Ross RS, Tangirala RK, Hsueh WA: Differential roles of cardiomyocyte and macrophage peroxisome proliferatoractivated receptor gamma in cardiac fibrosis. Diabetes 2008;57:2470-2479.

21 Kis A, Murdoch C, Zhang M, Siva A, Rodriguez-Cuenca S, Carobbio S, Lukasik A, Blount M, O'Rahilly S, Gray SL, Shah AM, Vidal-Puig A: Defective peroxisomal proliferators activated receptor gamma activity due to dominant-negative mutation synergizes with hypertension to accelerate cardiac fibrosis in mice. Eur J Heart Fail 2009;11:533-541.

22 Miard S. Fajas L. Atypical transcriptional regulators and cofactors of PPAR gamma. Int J Obes (Lond) 2005;29:S10-S12.

23 Tong Q, Tsai J, Tan G, Dalgin G, Hotamisligil GS. Interaction between GATA and the C/EBP family of transcription factors is critical in GATA-mediated suppression of adipocyte differentiation. Mol Cell Biol 2005;25:706-715.

24 Zhou Q, Guan W, Qiao H, Cheng Y, Li Z, Zhai X, Zhou Y: GATA binding protein 2 mediates leptin inhibition of PPAR 1 expression in hepatic stellate cells and contributes to hepatic stellate cell activation. Biochim Biophys Acta 2014;1842:2367-2377.

25 Fajas L, Landsberg RL, Huss-Garcia Y, Sardet C, Lees JA, Auwerx J: E2Fs regulate adipocyte differentiation. Dev Cell 2002;3:39-49.

26 Phanish MK, Wahab NA, Colville-Nash P, Hendry BM, Dockrell ME: The differential role of Smad2 and Smad3 in the regulation of pro-fibrotic TGFbeta1 responses in human proximal-tubule epithelial cells. Biochem J 2006;393:601-607.

27 Míguez DG, Gil-Guiñón E, Pons S, MartíE: Smad2 and Smad3 cooperate and antagonize simultaneously in vertebrate neurogenesis. J Cell Sci 2013;126:5335-5343.

28 Labbé E, Silvestri C, Hoodless PA, Wrana JL, Attisano L: Smad2 and Smad3 positively and negatively regulate TGFbeta-dependent transcription through the forkhead DNA-binding protein FAST2. Mol Cell 1998;2:109-120.

29 Zheng S, Chen A: Disruption of transforming growth factor-beta signaling by curcumin induces gene expression of peroxisome proliferator-activated receptor-gamma in rat hepatic stellate cells. Am J Physiol Gastrointest Liver Physiol 2007;292:G113-123.

30 Massagué J, Seoane J, Wotton D: Smad transcription factors. Genes Dev 2005;19:2783-2810. 


\section{Cellular Physiology Cell Physiol Biochem 2016;40:908-920 \begin{tabular}{l|l|l} 
DOI: 10.1159/000453149 & $\begin{array}{l}\text { O 2016 The Author(s). Published by S. Karger AG, Basel } \\
\text { www.karger.com/cpb }\end{array}$
\end{tabular} \\ Gong et al.: mSin3A-HDAC1-Smad3 Mediates PPAR $\gamma$ Inhibition by TGF- $\beta$}

31 Takahata M, Inoue Y, Tsuda H, Imoto I, Koinuma D, Hayashi M, Ichikura T, Yamori T, Nagasaki K, Yoshida M, Matsuoka M, Morishita K, Yuki K, Hanyu A, Miyazawa K, Inazawa J, Miyazono K, Imamura T: SKI and MEL1 cooperate to inhibit transforming growth factor-beta signal in gastric cancer cells. J Biol Chem 2009;284:3334-3344.

32 Tsuneyoshi N, Tan EK, Sadasivam A, Poobalan Y, Sumi T, Nakatsuji N, Suemori H, Dunn NR: The SMAD2/3 corepressor SNON maintains pluripotency through selective repression of mesendodermal genes in human ES cells. Genes Dev 2013;26:2471-2476.

33 Wotton D, Lo RS, Swaby LA, MassaguéJ: Multiple modes of repression by the Smad transcriptional corepressor TGIF. J Biol Chem 1999;274:37105-37110.

34 Wu JW, Krawitz AR, Chai J, Li W, Zhang F, Luo K, Shi Y. Structural mechanism of Smad4 recognition by the nuclear oncoprotein Ski: Insights on Ski-mediated repression of TGF-? signaling. Cell 2002;111:357-367.

35 Akiyoshi S, Inoue H, Hanai J, Kusanagi K, Nemoto N, Miyazono K, Kawabata M: The Ski oncoprotein interacts with the Smad proteins to repress TGF- $\beta$ signaling. Genes Dev 1999;13:2196-2206.

36 Sun Y, Liu X, Eaton EN, Lane WS, Lodish HF, Weinberg RA: Interaction of the Ski oncoprotein with Smad3 regulates TGF- $\beta$ signaling. Mol Cell 1999;4:499-509.

37 Izutsu K, Kurokawa M, Imai Y, Maki K, Mitani K, Hirai H: The co-repressor CtBP interacts with Evi-1 to repress transforming growth factor- $\beta$ signaling. Blood 2001;97:2815-2822.

38 Tao H, Shi K-H, Yang J-J, Huang C, Zhan H-Y, Li J: Histone deacetylases in cardiac fibrosis: current perspectives for therapy. Cell Signal 2014;26:521-527.

39 Salminen A, Kauppinen A, Kaarniranta K: AMPK/Snf1 signaling regulates histone acetylation: Impact on gene expression and epigenetic functions. Cell Signal 2016;28:887-895.

40 Wilkinson DS, Tsai WW, Schumacher MA, Barton MC: Chromatin-bound p53 anchors activated Smads and the mSin3A corepressor to confer transforming growth factor-beta-mediated transcription repression. Mol Cell Biol 2008;28:1988-1998.

41 Silverstein RA, Ekwall K: Sin3: a flexible regulator of global gene expression and genome stability. Curr Genet 2005;47:1-17.

42 Sahu SC, Swanson KA, Kang RS, Huang K, Brubaker K, Ratcliff K, Radhakrishnan I: Conserved themes in target recognition by the PAH1 and PAH2 domains of the Sin3 transcriptional corepressor. J Mol Biol 2008;375:1444-1456.

43 Ross S, Hill CS: How the Smads regulate transcription. Int J Biochem Cell Biol 2008;40:383-408.

44 Grzenda A, Lomberk G, Zhang JS, Urrutia R: Sin3: master scaffold and transcriptional corepressor. Biochim Biophys Acta 2009;1789:443-450.

45 Ji Q Hu H, Yang F, Yuan J, Yang Y, Jiang L, Qian Y, Jiang B, Zou Y, Wang Y, Shao C, Gong Y: CRL4B interacts and coordinates with SIN3A/HDAC complex to repress CDKN1A in driving cell cycle progression. J Cell Sci 2014;127:4679-4691.

46 Kao YH, Liou JP, Chung CC, Lien GS, Kuo CC, Chen SA, Chen YJ: Histone deacetylase inhibition improved cardiac functions with direct antifibrotic activity in heart failure. Int J Cardiol 2013;168:4178-4183. 